Sri Lankan Journal of Anaesthesiology 19(1) : 5 - 16(2011)

PRESIDENTIAL ADDRESS

\title{
HOW WE GOT TO WHERE WE ARE
}

\author{
Jayantha Jayasuriya \\ President, College of Anaesthesiologists of Sri Lanka 2010
}

The theme of this years' Scientific Session is "Reflecting.......Moving towards greater excellence". In keeping with this theme, what I plan to do in my presidential address is first to reflect on how we got to where we are.

Anaesthetics were administered in the United States of America from the early 1840's. What is recognised as the first successful general anaesthetic was administered at the Massachusetts General Hospital, Boston on $16^{\text {th }}$ October 1846 when William Thomas Green Morton gave ether to Edward Abbott for the removal of a tumour on the jaw. The news was carried on the next available ship to the United Kingdom and on $19^{\text {th }}$ December a dental surgeon James Robinson administered the first ether anaesthetic in the U.K. Two days later Listor performed an amputation under ether at the University College Hospital, London. In November 1847 James Young Simpson introduced chloroform into clinical practice as an anaesthetic.

The exact date when general anaesthesia was first used in Sri Lanka is not known. It is necessary at this stage to correct a wrong date which has got into print. The 1996 issue of our College journal carried an article $^{1}$ which said that the General Hospital Colombo was started in 1846 and the anaesthetic used then was chloroform. This is wrong on two counts. Firstly, the General Hospital, Colombo was started only in 1864 and not 1846. Secondly it was only in 1847 that chloroform came to be used as an anaesthetic. What has happened is probably a printer's error where the two figures 4 and 6 were juxtaposed. The wrong date in the 1996 article has also been quoted in a subsequent Presidential Address ${ }^{2}$.

Samuel Fisk Green graduated in medicine in 1845 and worked in Boston, Massachusetts until $20^{\text {th }}$
April 1847. He then set sail to join the American Ceylon Mission arriving in Point Pedro in north Sri Lanka on $6^{\text {th }}$ October 1847. Soon after his arrival: 'Mr M, a Tamil and Sanskrit pundit became seriously ill. The native physicians gave up his case as hopeless. After much hesitation....., the relatives decided to call in Dr Green. Dr Green diagnosed the case as an abscess in the abdomen and advised immediate operation. ...... cut open the abscess and cured him. Dr Green's fame spread. The doctor had removed the bowels out, adjusted them and re fixed them.",

In 1848 Green established the American Ceylon Mission Hospital at Manipay. He kept good records. In the first 13 months he treated 2544 patients, a little over a third were surgical cases. Green was also the surgeon at the Jaffna Friend-inNeed Society Hospital from 1850 to 1873 . Green was a prolific letter writer. The letters he wrote home were published after his death. ${ }^{4}$ In 1849 he wrote to his brother "I have removed lots of tumours, have operated for cataract several times, for strangulated hernia once, amputated an arm once ....removed several cancers; amputated fingers and toes and portions of the hand several times; treated a good many fractures....attended some very bad cases of childbirth ...." "I removed the left upper jaw and cheek bones for a cancerous fungus in the antrum filling the whole mouth and the left nostril.....performed successfully and repeatedly Dr Simm's famous operation....".

Although Green wrote about the surgery he carried out, nowhere in his letters does Green mention the use of anaesthesia. But circumstantial evidence would suggest that because he was working in Boston when the first anaesthetic was given he was aware of the use of ether as an anaesthetic and given the scope of surgery he performed, he may 
as well have been the first person to use ether in Sri Lanka.

The first reference to anaesthesia in clinical practice in Sri Lanka is in 1887 the year the Ceylon Medical Journal commenced publication. Schokman ${ }^{5}$ described seven surgical cases he had treated at Galle. He mentioned the use of chloroform in four of the cases. In one, a thirty one year old strong well made man with a hernia, was administered chloroform cautiously as the man had an enlarged heart. The pulse was reported to be irregular and intermittent. The patient was discharged home after twenty five days. In a second case, a forty year old man with a hernia, got sick under chloroform and coughed violently. He was a most troublesome patient disarranging dressings and not remaining still though advised". Could it be that he aspirated? Was his troublesome behavior due to hypoxia? He however recovered and was discharged home twenty five days after the operation.

On $13^{\text {th }}$ September 1887 , Schokman operated on a forty year old patient who had a massive ovarian tumour which kept refilling despite repeated aspiration. In the published report Dr Schokman wrote: "To my House Surgeon Mr Wijeyesekera my best thanks, for the admirable skill and care exhibited in chloroforming the patient and maintaining its actions thoroughly throughout the operation which lasted two and a half hours." $\mathrm{He}$ also noted that the "rapidity of patients recovery is worthy of note". 6 This must have been a creditable achievement because even some fifteen to twenty years later it was reported that "because surgery depended on chloroform, the surgeon didn't dare have a patient under anaesthetic for longer than an hour".

The first report of the use of anaesthesia in obstetrics in Sri Lanka was in 1889 when Leembruggen who was working at Panadura Hospital carried out manipulation under chloroform anaesthesia in two patients with dorso anterior right arm presentation. ${ }^{7}$

The same year Modder reported two cases treated at Kegalle. One was a 10 year old boy who presented with swelling of the throat and inability to swallow food or water after accidentally swallowing a chicken bone. The boy became exhausted by struggling for breath. Chloroform was at once given of which he took 50 minims ( 3 $\mathrm{ml}$ ) before he came under its influence. A laryngotracheotomy was performed. As soon as the wind pipe was opened and a tube inserted the boy began to breathe freely. The tracheal tube was taken out eight days later. ${ }^{8}$

Records show that till 1898 the General Hospital Colombo had only one surgeon and physician, the house surgeon used to administer the anaesthetic. Later the second and then the third physician had to alternate in administering the chloroform. As the physicians had to neglect their legitimate duties, representations were made on the need to appoint a full time anaesthetist. In 1904 Dr David Rockwood was appointed chloroformist which is what the anaesthetist was called those days. He was succeeded in 1909 by Dr Joseph (JS) de Silva. From 1912, Dr De Silva also functioned as the Lecturer in Anaesthetics and as the Lecturer in Materia Medica and Pharmacology at the Colombo Medical School. Dr De Silva became an expert at the use of chloroform and ether. $\mathrm{He}$ is on record using rectal ether for thyroidectomies - one such anaesthetic was witnessed by one of our former Presidents Vanniasingham who described it as 'a very satisfactory anaesthetic'.

In 1905, Sinnathamby reported the use of chloroform during a caesarean section. "Administration of chloroform commenced at 0255. Patient ready for operation at 0305 . ...... on the table for an hour.... Made an uninterrupted recovery and discharged in three weeks." 10

The same year, Nicholas Senn, Professor of Surgery at the University of Chicago visited Sri Lanka. About General Hospital Colombo, he wrote "chloroform is used as a general anaesthetic and in several thousand anaesthetics only two deaths occurred." 11 The mortality described by Senn compares favourably with that in the West. In 1901 Heineck gave a rate of 1 death per 3082 chloroform anaesthetics. ${ }^{12}$ Senn also visited Kandy Civil Hospital. He noted that "chloroform is the favoured anaesthetic. The hospital has a remarkable record in the treatment of tetanus, 13 cases without a death". ${ }^{11}$ 
1906 saw the first local publication relating only to anaesthetics when a paper read by WG Van Dort before a meeting of the Ceylon Branch of the British Medical Association was published in its journal. The paper was titled "On Stovaine - As a local and general anaesthetic. A brief review of recent articles on the subject in the medical press." ${ }^{13}$ Van Dort had no first hand knowledge of Stovaine. A colleague of his Dr George Thomasz during a visit to Paris had witnessed a number of operations been performed under anaesthesia induced by the injection of Stovaine into the subarachnoid space in the lumbar region. Stovaine was described as "a new anaesthetic which though hardly known here, and practically ignored in the UK, has...superseded cocaine.......as a local anaesthetic and promises to prove a formidable rival even to chloroform and ether". The paper concluded hoping that attention and interest was drawn "to an anaesthetic, which has so many advantages over chloroform and.... similar drugs that induce insensibility by inhalation - ...... cheaper, of reliable strength, perfectly safe, without any toxic or disagreeable effects ...... and so easily administered that a single surgeon unaided can now perform most operations in remote stations...."

Van Dort had a daughter, Claribel who was only the fourth female student to enter Ceylon Medical College and graduated with a distinction in Surgery. Claribel Van Dort is the first female doctor on record to have administered an anaesthetic in Sri Lanka. Claribel married her batch mate RL Spittel who went on to become a renowned surgeon and an authority on the native veddah community. The Spittels' opened a private nursing home and Claribel left government service to become the anaesthetist there. Claribel Van Dort is the trail blazer of all the female anaesthetists in Sri Lanka.

In 1908 Bartholomeusz who was House Surgeon, Government Civil Hospital, Kandy was presented with a patient who had a strangulated inguinal hernia with appendicitis who needed surgery urgently. Unfortunately, he "had no assistant at the time - the Medical Officer in charge being away on holiday... Chloroform was administered, the duty of the anaesthetist being undertaken by $\mathrm{Mr}$
Dharmaratne, the Apothecary." "14 The patient made a good recovery.

In 1912 RL Spittel described a 10 year old boy with a traumatic perforation of the stomach. "At the inception of anaesthesia, a large quantity of undigested rice was vomited which I afterwards ascertained he had partaken just before the accident occurred." Accident had happened ten hours before surgery. Apart from pyrexia on days one and two the "convalescence was uninterrupted and patient made a good recovery."

The same year Lucian de Zilwa described a female patient with a sloughing uterine fibroid. The patient was thin, anaemic and had a pulse rate of $120 / \mathrm{min}$. As she was getting worse by the day, eight days after admission it was decided to operate on her. I quote "owing to the fever and the general condition of the patient the anaesthetist declined to chloroform the case. ..... patient was getting worse.... knew only an operation could save her, I directed my house physician to anaesthetise the patient and performed an abdominal hysterectomy" ${ }^{\prime 16 . ~ T h e ~ p a t i e n t ~ d i d ~ w e l l ~}$ and was discharged home.

In 1913 Spittel described a case where he carried out the restoration of the nose by a chondroplastic operation. It was multi stage surgery involving four operations on the palate, building up a new nose using costal cartilage and a forehead flap. ${ }^{17}$ In 1915 Spittel described a case of ankylosis of the jaw treated by Murphy's operation. ${ }^{18}$ The airway with limited mouth opening, over-riding upper teeth and short tempero-mandibular distance would prove a challenge even today let alone in 1915. Unfortunately, there is no mention of the anaesthetic in either case but one can only admire the skill the anaesthetist must have possessed in maintaining the airway.

1915 also saw Lucian de Zilwa describe twelve laparotomies "in which ......., local anaesthesia was preferred to chloroform or ether. In every case general anaesthesia seemed fraught with danger, either owing to the age, or the weakness or the lung condition of the patient". The local anaesthetic used was Eudernine diluted four times with normal saline and injected into the skin. In six of the cases, chloroform or ether had to be 
given for a few minutes to permit the separation of adhesions or to cause relaxation of abdominal muscles. One of the patients was a thirty year old lady with a large cyst of the left ovary adherent to the posterior aspect of the uterus and walls of the pelvic cavity. The "operation lasted 2 hours and was done entirely under local anaesthesia. Perhaps under chloroform the operation would have taken half an hour less. But it is extremely doubtful if she would have survived the administration of chloroform during an hour and a half." 19

The same year, David $^{20}$ said that for operative treatment of hydrocoele: "I always prefer chloroform with or without ether, having previously prepared the patient with a hypodermic injection of morphia and hyoscine, local anaesthesia having proved unsuccessful on more than one occasion." This is the first reference in local literature on the use of pre-anaesthetic medication.

1915 also saw the publication by RL Spittel of a book titled 'A basis of surgical ward work'. ${ }^{21}$ The book sheds light on the state of knowledge and practice that existed in the country at that time. Ninety five years later, some of the things in the book are still valid.

On pre-operative fasting: "Food is not allowed for at least five hours before the operation. Liberal quantity of fluids is allowed up to six hours of the operation, and in reasonable quantity after this. In emergency cases which have recently had a meal, the stomach should be washed out".

Preparation by medical attendant: "try to gain the confidence of the patient and to allay his fear. Avoid anything tending to discouragement....". Make a complete examination of every patient to be operated on. Examine the heart, lungs and urine as a routine. The blood pressure should be taken. Any coexistent pathological condition must be corrected as far as possible before the operation. More or less prolonged preparation may be required in some cases.

Patients with lung disease: "If bronchitis is present, broncho-pneumonia is to be feared. Except in urgent cases, patients suffering from respiratory disease should have the operation postponed. If the operation cannot be postponed until the bronchitis is cured, creosotal $2 \frac{1}{2} 2$ drachms in the form of an enema with milk may be given night and morning."

Patients with heart disease: "When a heart lesion is fully compensated and moderate exertion fails to excite untoward symptoms, the operation can be safely done under a general anaesthetic". They did know about exercise tolerance even then!

Pre-medication: "Nervous patients should be ensured a good nights rest by a bromide draught or by 5 grains of veronal given at 5 or $6 \mathrm{pm}$ dissolved in plain hot tea and repeated at 9 or $10 \mathrm{pm}$.

In all patients about to undergo severe operations, save children, the very old and the septic or anaemic, give hypodermically one hour before the operation one of the following:

- Morphine sulphate grain $1 / 6-1 / 4+$ Atropine sulphate gr 1/250

- Morphine sulphate grain $1 / 6+$ scopolamine gr $1 / 150$

- Omnopon grain $2 / 3+$ scopolamine gr $1 / 150$ in 17 minims of water.

(1 grain $=0.064$ gramme $)$

These injections were said to produce an "agreeable indifference to the operation about to take place."

Preparation just before anaesthetising: “ ...to prevent shock, in all operations on poorly nourished patients warm clothing is imperative the limbs should be completely swathed in flannel bandage and warm socks worn. An enema of warm tea or coffee with sugar and brandy may be given to the patient before and after the operation". These look like precautions to prevent hypothermia though not recognised as such.

Chapter IV of Spittel's book dealt with what he called the after treatment. He said “...... A skilled anaesthetist will have his subject so lightly under anaesthesia that signs of recovery will be manifest almost as soon as the patient is transferred from the table to the bed. If the patient remains unconscious long after operation, it means that an unnecessary quantity of anaesthesia has been used". 
"The anaesthetist should always be by the patient until distinct signs of recovery are evident. i.e. he moves his head, opens his eyes or talks. When there is a risk of obstruction to respiration an assistant should be ready with a mouth gag and tongue forceps.... The best position for speedy recovery from anaesthesia is with the patient on his side if the nature of the operation permits it."

Management of postoperative complications were also dealt with. Persistent vomiting was treated with "stomach lavage with hot water containing sodium bicarbonate to remove the anaesthetic soaked secretions which is the chief cause of postanaesthetic vomiting". If the vomiting persisted the following were suggested:

- Mustard plaster or hot water bag to the pit of the stomach

- Sodium bromide 10 grain in a cup of black coffee or

- Cerium oxalate 5-10 grain with sodium bromide 20 grain in water.

- Maintain nutrition with nutrient enemata.

PAIN: Spittel said that pain developing a few hours after operation must have its cause inquired into. Suggested treatment for severe pain was:

- Hypodermic of morphine $1 / 6-1 / 4$ grain \pm atropine gr $1 / 150$

- Heroin gr $1 / 12$

- Veronal 5 gr; Trianol 30 grain; Potassium bromide 30 grain with chloral hydrate 10 grain.

SHOCK: Ether was described as been "always the anaesthetic of choice if shock is feared". To minimise shock the following were suggested

- Prevent cooling of large surface of the body during anaesthesia

- Careful anaesthetisation

- Avoidance of loss of blood

- In amputation, inject cocaine into main nerve trunks before division.

When signs of shock are manifest the following had to be done:

- Lower the head by raising the foot of the bed

- Keep patient dry and warm
- Ether 10 - 20 minims injected hypodermically

- Enema of hot strong coffee with $1 \mathrm{oz}$ of brandy

- Saline into a vein, subcutaneous or proctoclysis according to urgency of the case.

- Brandy 20 minims hypodermically, $1 \mathrm{oz}$ per oral or $2 \mathrm{oz}$ per rectal with an equal part of water.

- Coffee 2-4 oz per rectal

If shock persisted, "nutrient enemata are given every 2 hours. A good stimulating enema in practice is:

Black coffee $6 \mathrm{oz}$

Brandy $2 \mathrm{oz}$

Ammonium carbonate 20 grain

Tropium 10 minim."

Strophantin grain 1/60 intravenous was described as dramatic in its stimulating effect in profound cardiac exhaustion.

Spittel stressed that "only one or other should be given at a time and greatest discretion is necessary......for it is possible to run an already overworked heart to death by the abuse of stimulants. They should be given in exceptional cases and at critical intervals."

If a patient developed post operative pneumonia the treatment was

- Repeated dry cupping

- Applying a pneumonia jacket

- Frequent change of position

- Plenty of fresh air

- Oxygen when much of the lung is involved.

This was before the discovery of antibiotics. Note also that oxygen was given only when much of the lung was involved. It was not recommended even in profound shock. This was a time when oxygen was regarded with dread by patients as well as their relatives. Suggestions for its use generally meant impending death.

The first reference to pain relief during labour in Sri Lanka was in 1917. An editorial ${ }^{22}$ described the use of morphine and hyoscine analgesia at the 
De Soyza Lying in Home. It said that "In some patients it acted like a charm while in others the results have been disappointing. Effect on the child has been uncertain. Some were born asphyxiated (in two cases artificial respiration failed to resuscitate the children) while others were born with no sign of narcotization. Very good results have been observed in cases of premature rupture of membranes. To summarize: drug should not be used indiscriminately in every case as they might be harmful both to the mother and the child."

The same year a Dr Peterson described an operation he had carried out in the open in a tea estate. I quote from his memoirs: "A few weeks after qualifying, I was sent to act as District Medical Officer Deltota.....the next day I got a call to Galaha Estate. A boy who had been looking for firewood had fallen on to a recently pruned tea bush and been pierced in a number of places by its sharp edges...... I found the patient .... covered with a cloth still lying on the tea bush.......I decided to operate on the spot rather than take the risk of the patient dying on the way to the hospital. I taught the kangany's wife to help me chloroform the patient. ....I did it once to show her. Then I gave her the mask and said: '...everytime I nod, you must put two drops into this mask and hold it one inch from his nose'. She turned out to be a very good student...... Surgery was done and ...... when the pulse was not too bad, had him carried to the hospital...... on the eighteenth day the patient walked back to the estate - no transport being available." 23

The journal in 1919 carried advertisements for chloroform (which was mixed with ethyl chloride as being conducive to comfortable anaesthesia), hyoscine (recommended for twilight sleep) and also a text book of anaesthesia.

In 1921 Vairakiam had a patient with a perforation of the intestine complicating typhoid fever who was six months pregnant. Chloroform was used. "There was much anxiety after the operation that premature labour might take place, but the patient went on to full term."24

Gunaratnam Cooke operated on a 34 year old patient who had the 'largest ovarian cyst' he had seen in 1928. He gives details of the anaesthetic. ${ }^{25}$
Night before: Morphine grain 1/4 IM

0600: Morphine grain 1/4 + Scopolamine grain 1/150 IM

"Her eyes were tied up, her ears were plugged and she was carried into the theatre. Lumbar puncture was done. 60 minims of CSF withdrawn and 2 c.c. of stovaine in glucose and distilled water was introduced."

Just before surgery: Scopolamine 1/450 grain.

Gunaratnam Cooke said that "It would have been impossible to give this patient a general anaesthetic without subsequent pulmonary complications."

Although there were designated anaesthetists in General Hospital, Colombo this was not the case outside Colombo. Milroy Paul who was Surgeon at Jaffna Civil Hospital from 1931 to 1933 recollects "....conditions.... were such that we had to act as both surgeon and anaesthetist for those cases that could be done under local or spinal anaesthesia. Operations below the level of the umbilicus were done under heavy spinal administered by me. Upper limb operations were carried out under a brachial plexus block. One or two hernias, perhaps a haemorrhoid or an operation for the cure of hydrocoele and upper and lower limb amputations were carried out before 11 am at which time Dr Jansen would arrive, now to serve as anaesthetist". Jansen was the Eye surgeon and he would administer chloroform for laparotomies. Paul was very impressed with Jansen's versatility. ${ }^{26}$

Dr Anthony Lucas who started his anaesthetic training in 1929 was the first Sri Lankan to proceed to the UK to obtain further qualification in anaesthesia. He was successful in 1935 at the first ever Diploma in Anaesthesia examination. $\mathrm{He}$ was in fact the first person east of Suez to pass this examination. On his return he succeeded Dr Joseph Silva.

Even at this stage, spinal anaesthetics were still administered by the surgeons. In 1936, Sinnathamby described in detail his use of spinal anaesthesia for surgery of the enlarged prostate. ${ }^{27}$ "The anaesthetic used by me was...stovaine $2 \mathrm{cc}$ preceded in some cases by the injection of 
morpine gr 1/4 with atropine $1 / 150$ gr half an hour before the operation." He went on "the only complication that may follow spinal anaesthesia is shock and the sudden fall of blood pressure during and after the operation. This .... is anticipated by suitable preparation of the patient ...... and spinal anaesthesia is withheld in all cases where systolic blood pressure is < $100 \mathrm{~mm}$ Hg." Patient preparation consisted of

- Cardiac stimulants

- Glucose orally and per rectum 24-48 hours before the operation

- Bandage all limbs to counteract the sudden fall in blood pressure

- Keep patient head slightly down from the time that the anaesthesia begins until all sensation in the legs has returned.

With these precautions he said he has not had a single case which caused him anxiety though some of the patients were between 80-90 years of age.

Sinnathamby also described a 76 year old patient with an enlarged heart, feeble heart sounds scarcely audible over the precordium, systolic blood pressure $110 \mathrm{~mm} \mathrm{Hg}$, radial pulse soft and low tension. The patient needed a suprapubic catheter but "was reluctant to use local anaesthesia considering the poor condition of the tissues ...... and the low blood pressure".

"When the condition was explained to our senior anaesthetist he volunteered to administer a general anaesthetic, though he was very reluctant to do so. By the help of his expert anaesthesia, I was able to drain the bladder through a small incision...... The patient stood the operation well...."27

In 1939, Wickramasuriya ${ }^{28}$ wrote on maternal mortality and morbidity in Ceylon. 130 or $13 \%$ of the total fatalities were due to complications of labour and 36 of these deaths $(3.6 \%$ of total fatalities) were due "to post operative shock following obstetric operation." Wickramasuriya commented "there is .....no doubt that chloroform is a dangerous anaesthetic to use in case of protracted labour with its accompanying acidaemia. Many post operative deaths are undoubtedly due to chloroform. In most of the large maternity hospitals in Great Britain gas and oxygen and spinal anaesthesia have displaced chloroform"

The use of chloroform in obstetrics continued. In $1950 \mathrm{P}$ de S Wijesekera wrote "In Ceylon, chloroform is the drug that is most commonly used in obstetric practice......its disadvantages outweigh the advantages ...... now rarely used in $\mathrm{UK}^{, 29}$

ATS Paul had to have a tooth extracted under anaesthesia in 1940. Dr Balendra, the dentist had imported the McKesson apparatus and Paul was to be the first patient in whom it was used. Paul was accompanied by a fellow student S Ponnambalam. According to Paul, Ponnambalam saw Paul struggling in the chair and took off in panic. ${ }^{30}$ One can only speculate whether this experience of seeing a dentist dabbling in anaesthesia is what prompted Ponnambalam to take up a career in anaesthesia. Ponnambalam became the second President of our College. After the anaesthetic, Paul cycled home alone. Luckily for him, the roads in Colombo were not as congested then as they are now!

Thanks to the recollections of Lucas ${ }^{31}$, BS Perera ${ }^{32}$ and Vanniasingham ${ }^{9}$ we know what equipment was in use in the 1930s and 1940s. Anaesthetics were given using the Silk inhaler which was a cylindrical cone made of celluloid with one end closed off. The closed end had moderate sized perforations to allow air to be drawn in by the patient's respiration. A folded piece of lint was pushed through the open end to the bottom of the other end and one dram of chloroform was poured on to the lint. The mask was then held over the patients nose and closed mouth about $1 / 2$ " above the face. Sometimes a catheter with oxygen was introduced under the mask. Intermittently the anaesthetist inhaled the mask to see that the chloroform was still there. If no chloroform was smelt, a further 1 dram of chloroform and 2 drams of ether was poured on to the lint; Schimmelbusch mask: The metal frame was covered with lint and chloroform or ether was poured onto the lint and the mask held above the face. In the late 1940's the Junker chloroform bottle was in use. Here the chloroform is in a bottle and fresh air is driven through the bottle by pressure on the bellows. The 
supply of anaesthetic was stopped when the bellows was not squeezed. Another advantage was that the anaesthetist did not inhale the anaesthetic which happened with the earlier masks. The hook on the Junker bottle was to allow the bottle to be hung from the lapel of the anaesthetist's coat.

Today, the ECG, oxygen saturation in the blood, carbon dioxide in the expired air and blood pressure are all measured by automated machines and displayed instantaneously on a screen. Compare this with what was used even upto the early 1970's which was finger on the pulse and hand on the bag - the rhythmic movement of which indicated the patient was breathing. This was supplemented by manual measurement of blood pressure. The first mention of continuous automated monitoring in Sri Lanka is by Rasiah ${ }^{33}$ who mentions that during neurosurgical operations in the 1970's a Cortell Keating pulse monitor was used. Monitors however are not infallible and will only indicate that something is amiss. They can only complement and cannot replace the presence of a vigilant anaesthetist who has to work out why something is amiss.

During the Second World War British Army anaesthetists in Ceylon had been amazed to see our anaesthetists using chloroform with such confidence and ease and had tried using it on their cases. Vanniasingham ${ }^{9}$ quotes Lucas that a couple of their patients died one after another. They probably made the mistake of approximating the mask tightly to the face so that in addition to cutting off additional air and oxygen, there was also carbon dioxide accumulation which probably led to ventricular fibrillation. The army doctors were probably the first to use the intravenous induction agent thiopentone sodium in Sri Lanka.

With the return from the UK after obtaining the Diploma in Anaesthesia Dr JLC (Laddie) Fernando in 1947 and Claude Umagiliya in 1948, nitrous oxide and Boyle's apparatus came into regular use. They were the first to use neuromuscular blocking agents - short acting relaxants for intubation and d-tubocurarine and gallamine for longer operations. Respiration was controlled with carbon dioxide absorption by soda lime. Endotracheal intubation became common place.
More anaesthetists returned after obtaining qualifications. Charles Herat Gunaratne in 1951, followed by Richards, Ponnambalam and BS Perera with the two part DA which entitled them subsequently to the Fellowship at that time of the Faculty of Anaesthetists of the Royal College of Surgeons. Vanniasingham returned in 1954 having been one of 16 successful candidates out of 160 who sat for the very first Fellowship examination.

A report by the $\mathrm{WHO}^{34}$ in 1955 said that in the General Hospital, Colombo the "anaesthetic techniques are in conformity with the teaching of today. (However) the situation in the Provincial Hospitals was and still is pretty desperate. In practically all outstation hospitals, anaesthesia is carried out by medical officers who have had no or at the most a very superficial training in anaesthesia."

Closed heart surgery was first performed in the late 1950s with first E W Anderson of Denmark and later Ian English from UK as anaesthetist. BS Perera and Ponnambalam took over and heart surgery under surface hypothermia was performed.

BS Perera was also the first person to use induced hypotension in Sri Lanka in 1955. At a time when there were no ventilators and hardly any monitoring Perera did a series of 136 cases of Wertheim's hysterectomy under hypotensive anaesthesia without a single fatality. ${ }^{32}$ Open heart surgery under cardio-pulmonary bypass was first performed in 1965.

Charles Herat Gunaratne was the first Consultant appointed outside Colombo when he was appointed to Kandy in 1955 following the WHO report. He was succeeded in 1956 by Vanniasingham.

Upali Weerakkody introduced epidural and caudal analgesia for surgery at the General Hospital, Kandy in 1967. He reported a personal series of 246 cases - 214 lumbar epidurals and 32 caudals. The series included two thyroidectomies and two of the patients had an epidural catheter for postoperative pain relief. ${ }^{35}$

Commencement of cardio-pulmonary bypass surgery was the impetus for the establishment of 
the country's first ICU serving both medical and surgical patients at General Hospital Colombo in 1968. Dr Thistle Jayawardene was in charge and he is the pioneer intensivist in Sri Lanka. It took 12 years before a second ICU was opened at Teaching Hospital, Peradeniya in 1980. In Jaffna in the mid 1970s both medical and surgical patients were ventilated in the thoracic unit. ${ }^{36,37}$ In Kandy too, patients were ventilated in the wards. A basic ICU was opened in Kandy around 1982. The ICU at Sri Jayawardenapura was commissioned in late 1983 and an ICU in Jaffna was established in 1984 . Today there are nearly 75 adult ICUs in the country managed by anaesthetists. There have been original contributions by Sri Lankan anaesthetists to the management of critically ill patients. Karalliedde and Senanayake ${ }^{38}$ were the first to describe the intermediate syndrome in organophosphate poisoning. In 1997 Deepthi Attygalle and Rodrigo $^{39}$ pioneered the use of magnesium sulphate in the management of moderate to severe tetanus avoiding sedation, paralysis and mechanical ventilation.

Anaesthetists went outside the operation theatre and intensive care units. The first pain clinic for the management of chronic pain was established at the General Hospital, Colombo by Sylvia Perera, TW Goonawardena and Vamadevan in the 1980s. Sylvia Perera also pioneered the use of acupuncture.

Kandy led the way with anaesthetic assessment clinics where patients with medical problems awaiting surgery are assessed by anaesthetists and optimised prior to surgery.

\section{Literature}

One feature that has stood out in this journey is the complete absence of any contribution to literature by Sri Lankan anaesthetists until 1955 when five papers were published. Four in the Journal of the Jaffna Clinical Society by Kalpage ${ }^{40}$, Ponnambalam $^{41}$ Ponnambalam and Vanniasingham $^{42}$ and Sivasubramaniam and Kalpage $^{43 .}$ Vanniasingham ${ }^{44}$ wrote to the Journal of Ceylon Obstetric and Gynaecological Association.

The first publication by a Sri Lankan in an international anaesthetic journal was in 1958, but the Sri Lankan contributor was not an anaesthetist but a surgeon. Navaratne who later became Professor of Surgery was the co-author of a paper published in Acta Anaesthesia Scandinavia on the use of mephenesin in the management of tetanus. ${ }^{45}$ The first Sri Lankan anaesthetist to have a paper published in an international journal was TW (Jumbo) Goonawardene who wrote to the British Journal of Anaesthesia in $1967 .{ }^{46}$

There were a number of publications in the 1970s dealing with management of patients in the ICU at Colombo. Jaffna also produced a commendable output of anaesthetic literature in the $1970 \& 80$ s. This dried up with the onset of the civil conflict but Ganeshamoorthy still produced two more papers describing how they were coping under the circumstances. From 1984 to 1989 there was a shortage of anaesthetic gases and the use of inhalation anaesthesia declined from 89\% in 1984 to $39.5 \%$ in 1988 with an increase in the use of total intravenous anaesthesia (mainly ketamine), regional techniques and infiltration analgesia. ${ }^{47}$ There was a total interruption of the supply of anaesthetic gases in 1990 and from June to December of that year the use of intravenous anaesthesia rose to $80 \%{ }^{48}$

Our College Journal was started in 1984. The first issue consisted of only four pages and from that beginning it has now developed into a journal that comes out twice a year - the two issues last year contained 102 pages.

\section{Excellence}

\section{Moving towards greater}

I am going to briefly reflect now on a couple of areas where I feel there is scope to move towards greater excellence.

\section{Corporate}

On 02.10.1957 the Ceylon Society of Anaesthetists was inaugurated. It held only one meeting and was dissolved in 1967 and replaced by the Association of Anaesthetists of Ceylon. In 1971 the College of Anaesthesiologists of Sri Lanka was formed. The history of the Association and the College has been dealt with by others before me so I will not dwell on it today except to say that the first Scientific Sessions was held in 
1984 during the Presidency of Dr Thistle Jayawardene whose brain child it was. Earlier this month the constitution of the College was amended to allow the setting up of a Faculty of Critical Care Medicine and a Faculty of Pain Medicine. This should help us move towards achieving greater excellence in the delivery of service and training in these two areas.

\section{Research}

There has been very little research done compared to the output of audits. I will mention two studies which show there is scope to move forwards. The first compared blowing up a balloon at regular intervals after abdominal surgery against conventional chest physiotherapy and steam inhalation. There was no difference between the two on the incidence of respiratory complications. ${ }^{49}$ Although the authors did not specifically look into it, blowing the balloon would seem to be more manpower and cost effective especially in the setting of a developing country. The second is a study by Vignakaran and Wijayasuriya $^{50}$ who looked at the effect of giving oral sildenalfil to neonates with congenital diaphragmatic hernia. Sildenafil therapy was associated with a significantly lower mortality. The number of patients in both studies was small, but it seems worth doing a controlled study with larger number of patients.

\section{Governance}

Good governance requires that we look at, learn from and improve our practice. In 1973 Karalliedde and colleagues ${ }^{51}$ looked at 9274 anaesthetics administered at Ratnapura over a 15 month period. There were thirteen cardiac arrests and seven deaths.

The authors were frank in expressing their opinion that seven of the cardiac arrests and three of the deaths could have been prevented with greater care and more freely available facilities for preoperative investigation and better equipped postoperative recovery rooms.

In 1984, Ganeshamoorthy ${ }^{52}$ looked at 53,288 anaesthetics administered in Jaffna over a four year period. There were four deaths attributed solely to anaesthesia. i.e. 1 in 13,322 which compared favourably with figures from the $\mathrm{UK}^{53}$ of 1 in 10,000 deaths attributed solely to anaesthesia.
Although there have been many audits after that looking at various specific aspects of anaesthetic care, there is no national or institution wide study looking at the total process of delivery of anaesthetic care.

The reporting of critical incidents which was imported into anaesthesia from the near miss reporting system used in aviation has now become an accepted way of looking at things that go wrong in an attempt to learn why things went wrong so that corrective action can be taken. Incident reporting was introduced to Sri Lanka in the mid 1990s. Jeewani Jayawardene ${ }^{54}$ published an analysis of critical incidents reported at the National Hospital of Sri Lanka from 1994-1996 and Thilakaratne and Rodrigo ${ }^{55}$ looked specifically at pharmacological incidents. The number of incidents reported during that period was in the best year only $0.038 \%$ compared to $0.5-2 \%$ in reported series from other countries. Unfortunately incident reporting is at present virtually nonexistent in Sri Lanka. Governance is an area where we can move towards achieving greater excellence.

To conclude, from the time of Schokman's house surgeon Wijayasekera, Peterson getting the wife of a kangany, Bartholomeusz an apothecary, and Lucian de Zilwa his house surgeon over-ruling the anaesthetist to administer anaesthesia we have come a long way. From the cursory three day training that existed even as late as 1940s, there is now a structured competency based training programme leading to an internationally recognised postgraduate degree. Having started off as a service requirement to facilitate surgery, anaesthetists now look after the patients both before and after the operation. Optimising them for the anaesthetic before the operation and managing pain, fluid balance and nutrition after the operation. We are what can be called perioperative physicians. The skills of anaesthetists were frequently made use of in stabilising victims of numerous terrorist related incidents. There are anaesthetists who have been Board certified by the Postgraduate Institute of medicine as specialists with a special training in Intensive Care. Anaesthetists are involved in pain management both acute and chronic, provide training in cardiopulmonary resuscitation and primary trauma care 
and teach both basic and applied sciences to undergraduates and postgraduates. Time has allowed me to touch only on some aspects of how we got to where we are. There are many other noteworthy contributions to the development of anaesthesia and intensive care in Sri Lanka especially in recent times which again time does not allow me to go into. It has been a long journey from the time of SF Green and Claribel Van Dort. One that we can justifiably be proud of.

\section{References}

1. Amarasekera S. Twenty five years of service Review and Renew. Jnl of the College of Anaesthesiologists of Sri Lanka, 1996, VI, 1-3

2. Fernando C. Presidential Address - Reaching towards island wide excellence. Sri lankan Jnl of Anaesthesiology, 2007, XV, 67-73

3. Mills BA. Modern Medicine and the American Ceylon Mission in the North. Journal of the Jaffna Clinical Society. 1966, III, 10-20.

4. Cutler Ebenezer. Life and Letters of Samuel Fisk Green, M.D.of Green Hill. 1891 Green Hill USA. (Reprint Asian Educational Services, New Delhi 2004.)

5. Schokman GP. Notes of some surgical cases treated in the General Hospital, Galle. CMJ, 1887, 1, 74-78.

6. Schokman GP A case of ovarian tumour treated at General Hospital, Galle. CMJ, 1888, 2, 117-8.

7. Leembruggen WE. Two cases of difficult labour. CMJ, 1889, 3, 131.

8. Modder EE. Two surgical cases treated in the Government Civil Hospital, Kegalle. CMJ, 1889, 3, 64-6.

9. Vanniasingham TW. Some personal reflections on the development of anaesthesia in Sri Lanka. Sri Lanka Jnl of Anaesthesiology. 2009, XVII(2), 99102

10. Sinnatamby M. A case of achondroplasia in which Caesarean Section was successfully performed. Jnl Cey Br BMA, 1905, II, 72-5.

11. Senn N. Around the World via India: A Medical Tour. 1905.

Chicago: American Medical Association Press.

12. Heineck AP. General and Local Anaesthesia. 1901. (Reprinted 2008 by Bibilioprint, USA)

13. Van Dort WG. On Stovaine as a local and general anaesthetic. (Review of recent articles in the medical press). Jnl Cey Br BMA, 1906, 3, 20-25.

14. Bartholomeusz FR. A case of strangulated inguinal hernia with appendicitis. $\mathrm{Jnl} \mathrm{Cey} \mathrm{Br}$ $B M A, 1908,6,6-7$.
15. Spittel RL. Notes on cases of perforation of the stomach and duodenum. Jnl Cey Br BMA, 1912, 9, 11-16.

16. de Zilwa L. Notes on some gynaecological cases. Jnl Cey Br BMA, 1912, 9, 39-41.

17. Spittel RL. Complete restoration of nose by a chondroplastic operation. Jnl Cey Br BMA, 1913, 10, 50-53.

18. Spittel RL. A case of ankylosis of the jaw treated by Murphy's osteoplastic operation. $\mathrm{Jnl} \mathrm{Cey} \mathrm{Br}$ $B M A, 1915,12,34-35$.

19. de Zilwa L. Twelve consecutive cases of abdominal sections under local anaesthesia. Jnl Cey Br BMA, 1915, 12, 46-50.

20. David I. Operative treatment of vaginal hydrocoele. Jnl Cey Br BMA, 1915, 12, 50-51.

21. Spittel RL. A Basis of Surgical Ward Work. Colombo, Ceylon Examiner Press. 1915.

22. Editorial: Twilight sleep. Jnl Cey Br BMA, 1917, 14, 59-61.

23. Peterson PRC. Great Days: Memoirs of a Ceylon Government Medical Officer of 1918. Ed Manel Fonseka. Colombo: Social Scientists Association. 2004.

24. Vairakiam SA. Notes on a case of perforation of the intestines complicating enteric in the sixth month of gestation. Jnl Cey Br BMA, 1921, 18, 3940.

25. Cooke Gunaratnam. Unusually large ovarian cyst removal under twilight sleep and spinal analgesia. Jnl Cey Br BMA, 1928, 25, 18-20.

26. Paul M. Surgery in the Jaffna Civil Hospital 1931-

33. Jaffna Med Jnl, 1979, XIV, 10-19.

27. Sinnathamby GS. Treatment of enlarged prostate in the very aged. Jnl Cey Br BMA, 1936, 33, 14-34.

28. Wickramasuriya GAW. Maternal Mortality and Morbidity in Ceylon. Jnl Cey Br BMA, 1939, 36, 79-106.

29. Wijesekera P de S. Pain in childbirth. Jnl Cey $\mathrm{Br}$ $B M A, 1950,45,20-26$.

30. Paul ATS. Anaesthesia over five decades - a personal experience. Jnl of the College of Anaesthesiologists of Sri Lanka 1992, 2, 29-30.

31. Nihalsinghe K. Presidential Address - Evolution of the anaesthetic practice and training in Sri Lanka. Jnl of the College of Anaesthesiologists of Sri Lanka, 1988, 1, 103-110

32. Perera BS. Personal communication.

33. Rasaiah BW. A short experience of anaesthesia for neurosurgery. Jnl of the Colombo Gen Hosp. 1972, 3, 116-126.

34. WHO: Final Report on Training of Anaesthetists and Operating Room Nurses. WHO Project: Ceylon 27. 1956. WHO Regional Office for South East Asia. 
35. Weerakkody U. Epidural and caudal analgesia. Jnl Colombo Gen Hospital, 1971, 2, 67-73

36. Nirmalananthan S. Treatment of tetanus with total muscle relaxation. Jaffna Mdl Jnl, 1974, XII(1), $18-20$

37. Mahendran S, Ratnam I, Natkunam R. Intermittent Positive Pressure Ventilation in a Provincial Hospital. Jaffna Mdl Jnl, 1976, 13, 51-53

38. Senanayake N, Karalliedde LD. Neurotoxic effects of organophosphorous insecticides. New Engl J Med, 1987,316, 761-763

39. Attygalle D, Rodrigo N. Magnesium as first line therapy in the management of tetanus: a prospective study of 40 patients. Anaesthesia, 2002, 57, 778-817

40. Kalpage Q. Changing horizons - anaesthesia. Jnl Jaffna Clinical Soc., 1955,2, 108-111

41. Ponnambalam S. Haemorrhage during surgery. Jnl Jaffna Clinical Soc., 1955,2, 166-169

42. Ponnambalam S, Vanniasingham TW. Thiopentone sodium in anaesthesia. Jnl Jaffna Clinical Soc., 1955,2, 130-135

43. Sivasubramaniam P, Kalpage Q. General anaesthesia for eye surgery. Jnl Jaffna Clinical Soc., 1955,2, 136-142

44. Vanniasingham TW. Vomiting in obstetric anaesthesia. Jnl Ceylon Obstetric \& Gynae Association, 1955, 2, 49-54.

45. Anderson EW, Navaratne RA. Tetanus: a review of 356 cases with special reference to treatment with mephenesin. Acta Anaes Scand, 1958, 2, 8189

46. Goonawardene TW. An unusual case of respiratory obstruction following anaesthesia - a case report. BJA 1967,39, 983-5

47. Ganeshamoorthy R, Sripathy A, Murugesampillai $M$. Anaesthesia in the face of gas shortage -5 year experience in a teaching hospital. Jnl of the College of Anaesthesiologists of Sri Lanka 1990, 1, 118120

48. Ganeshamoorthy R. Anaesthesia in a Civil War situation - an experience in Jaffna. Jaffna Mdl Jnl, 1995, 25, $1-10$

49. Gunasekera CDA, Jayatileke JM, Medagedera RMD. Regular balloon inflation as an alternative to steam inhalation for the prevention of postoperative pulmonary complications. Kandy Med Jnl, 1997, 6, 40-43

50. Vignakaran S, Wijayasuriya PMS. Sildenafil can improve the clinical outcome in neonates with congenital diaphragmatic hernia. Sri Lanka Jnl of A'logy, 2006, XIV(1), 53-60.

51. Karalliedde LD, Vinitharatne JKP, Niles RJ, Amarasinghe KB. Cardiac arrests and deaths associated with anaesthesia at a Provincial Hospital. Ceylon Mdl Jnl, 1975, 20, 166-172

52. Ganeshamoorthy R. Respiratory failure during and after anaesthesia: a four year survey. Jnl of the College of Anaesthesiologists of Sri Lanka, 1985, 1, 9-14

53. Lunn JN, Mushin WW. Mortality associated with anaesthesia. Anaesthesia, 1982, 37, 856

54. Jayawardene Jeewani. Catastrophes in Anaesthesia - an analysis of critical incidents reported in the National Hospital of Sri Lanka from 1994-1996. Jnl of the College of Anaesthesiologists of Sri Lanka 1997, VII, 33-39

55. Tilakaratne P, Rodrigo N. Pharmacological incidents - How can we prevent them? Jnl of the College of Anaesthesiologists of Sri Lanka 1997, VII, 40-43 